\section{Gender differences and psychotropic polypharmacy in psychiatric patients in Brazil: a cross-sectional analysis of the PESSOAS Project}

\author{
Diferenças de gênero e polifarmácia psicotrópica \\ em pacientes psiquiátricos no Brasil: uma análise \\ transversal do Projeto PESSOAS
}

\section{Diferencias de género y polifarmacia psicotrópica en pacientes psiquiátricos en Brasil: un análisis transversal del Proyecto PESSOAS}

Juliana de Oliveira Costa 1 Maria das Graças Braga Ceccato 1 Ana Paula Souto Melo 2 Francisco de Assis Acurcio 1 Mark Drew Crosland Guimarães 3

doi: 10.1590/0102-311X00168915

\begin{abstract}
We aimed to estimate the prevalence and correlates of psychotropic polypharmacy in Brazilian psychiatric patients by gender. Sociodemographic, behavioral and clinical data were obtained through face-to-face interviews and medical charts of 2,475 patients. Psychotropic polypharmacy was defined as the use of two or more psychotropic drugs and occurred in $85.7 \%$ of men (95\%CI: $83.6 \%-87.6 \%$ ) and 84.9\% of women (95\%CI: $82.8 \%-86.8 \% ; p>0.05$ ). The mean number of psychotropic drugs/patient was $2.98 \pm 1.23$ and most common combinations included antipsychotics. Multivariate analysis showed that for both genders, previous hospitalization, severe mental illness, multiple psychiatric diagnoses and an insufficient number of professionals in the health care unit was associated with psychotropic polypharmacy. However, other correlates such as inpatient care, use of non-psychotropic drugs, living in unstable conditions and current smoking vary among them. Psychotropic polypharmacy was a common practice in this national sample. The results highlighted the need for national guidelines to manage patients with mental illness, considering the difference among genders and disease severity, to reduce the burden of polyphamacy in this population.
\end{abstract}

Polypharmacy; Psychotropic Drugs; Mental Disorders; Gender and Health

\author{
Correspondence \\ J. O. Costa \\ Faculdade de Farmácia, Universidade Federal de Minas Gerais. \\ Av. Antônio Carlos 6627, Belo Horizonte, MG 31270-901, \\ Brasil. \\ juliana.olic@gmail.com \\ 1 Faculdade de Farmácia, Universidade Federal de Minas \\ Gerais, Belo Horizonte, Brasil. \\ 2 Faculdade de Medicina, Universidade Federal de São João \\ del-Rei, Divinópolis, Brasil. \\ 3 Faculdade de Medicina, Universidade Federal de Minas \\ Gerais, Belo Horizonte, Brasil.
}




\section{Introduction}

Mental disorders are among the five most important contributors to the global burden of disease and disability. Together with substance use disorders, they account for $7.4 \%$ of disability-adjusted life-years lost and were the leading cause of years lived with disability worldwide in 2010 1. In Brazil, the prevalence of at least one lifetime mental disorder was $44.8 \%$ in a large metropolitan area, with an estimated lifetime risk at age 75 of $57.7 \% 2$.

Gender plays a vital role in neurobiological aspects, psychosocial factors, and behavioral patterns in several psychiatric disorders. Gender differences have been reported in the prevalence, type of diagnosis, treatment and behavior among individuals with mental disorders 3 , with higher prevalence of disorders among boys during childhood and among women during adulthood 1,4. Women have a higher prevalence of affective and anxiety disorders while men have higher rates of substance use and antisocial personality disorders $1,2,5,6,7,8$.

The use of psychotropic medicines has been the main strategy for treatment of these individuals. In Brazil, their utilization appears to be three times higher among women, especially benzodiazepines and antidepressants 9,10. Women also seek and use health services more often than men 10. Drug interactions and adverse events commonly occur with these medications, and are responsible for the most common cause of hospitalizations due to adverse drug events 11.

Polypharmacy has no uniform definition, and can be classified as the number of medicines taken simultaneously, corresponding to the use of two or more medicines or be evaluated as minor polypharmacy (concurrent use of two to four medicines) and major polypharmacy (concurrent use of five or more medicines) 12 . Concerns with polypharmacy include the possibility of cumulative toxicity and worsening adherence by increasing the complexity of treatment 13,14. In addition, they increase the costs of therapy with strategies that are not well established in the literature 14.

The prescription of multiple drugs for patients with mental illnesses has been an increasingly common practice without clear clinical effectiveness and with a potential likelihood of adverse drug reactions, despite controversies 13,15. Accordingly, the aim of this study was to assess the prevalence and correlates of psychotropic polypharmacy, defined as the use of two or more psychotropic medicines from the same or a different pharmacological class, with emphasis on gender differences, in a national representative sample of psychiatric patients under care in Brazil.

\section{Methods}

This study is part of a national multicenter study among psychiatric patients in Brazil, as described in detail in previous publications $16,17,18$. Briefly, we conducted a multicenter cross-sectional study in 2006 in 11 public psychiatric hospitals and 15 outpatient Psychosocial Care Centers (CAPS). CAPS are public mental health outpatient clinics created to progressively reduce psychiatric hospital care. They provide consultations, therapeutic and creative workshops, physical and recreational activities, art therapy, and medication on a daily basis during week days 19 , while hospitals attend patients under closed regimens for an average of 20 days.

Medications provided at CAPS include at least those of the Brazilian National List of Essential Medicines (RENAME in portuguese), while local health services can provide other medications as needed. In 2006, the list included three options of antipsychotic agents (haloperidol, chlorpromazine, lithium carbonate), two anxiolytics, hypnotics and sedatives (diazepam, clonazepam), two antiparkinsonian (biperiden, levodopa+carbidopa), four antidepressants (fluoxetine, amitriptyline, nortriptyline, clomipramine) and four antiepileptics (carbamazenine, valproatesodium, phenytoin and phenobarbital) 20 . In addition to the list, the provision of medicines in the hospitals depends on each institution's standard practices.

We obtained a two-stage probability sample, proportional to the type of care (inpatient or outpatient) and the national distribution of the reported AIDS cases by region. Eligibility criteria included adult patients ( $\geq 18$ years old) under psychiatric care in hospitals or adult CAPS, who were able to answer the questionnaire and to sign the informed consent, as assessed by a mental health professional interviewer. We obtained demographic, socioeconomic, behavioral, and selected clinical data 
through a semi-structured interview. Medical data, including psychiatric diagnoses and prescriptions, was obtained from medical charts. Protocol, questionnaires and procedures were tested in a pilot study, described previously 18 .

The project was approved by the participating centers and by the Ethics Research Committee of the Minas Gerais Federal University (COEP/UFMG, Etic 125/05) and the National Ethics Research Committee of the Brazilian Ministry of Health (CONEP 592/2006).

\section{Events and explanatory variables}

Psychotropic polypharmacy, the event of interest in this study, was defined as the concurrent use of two or more psychotropic medicines registered in the medical charts at the time of data collection. Patients under psychotropic polypharmacy were compared with patients on monotherapy and those who did not use any medication. For the purposes of this analysis, the potential explanatory variables were grouped into individual and institutional characteristics.

The individual characteristics investigated were: (a) demographic: age ( $\geq 40$ or $<40$ years old), marital status (single/divorced/widowed or married/stable union); (b) socioeconomic: education level ( $\geq 5$ or $<5$ years of study), place of residence (unstable or stable), health insurance (yes or no), family income in the last month ( $\leq$ USD 200 or > USD 200); (c) behavioral: lifetime cigarette smoking (current smokers or ex-smokers or non-smokers), lifetime alcohol or illicit drug use (yes or no); (d) medical information: self-reported previous hospitalization (yes or no), non-psychotropic medicine prescription (yes or no), main psychiatric diagnosis, number of psychiatric diagnoses, non-psychiatric comorbidities and number of non-psychiatric diagnoses. Explanatory characteristics related to the mental health service were type of service setting (psychiatric hospital or CAPS), number of professionals, and availability of medicines in the centers.

Current place of residence was defined as unstable (living in shelters, hostels, hospital or on the streets) and stable (living in a house or apartment). Current smokers were defined as those who reported smoking at least one cigarette per day regardless of the length of smoking period at the time of the interview, and ex-smokers those who used to smoke, but were not smokers at the time of the interview. Lifetime alcohol or illicit drug use was defined as the use of alcohol or any illicit drug regardless of the frequency or dose.

Previous hospitalization was defined as self-reported hospitalization before the date of the interview. The main psychiatric diagnosis was extracted from the patient's chart and described according to the 10th revision of the International Classification of Diseases (ICD-10) 21. In the case of more than one diagnosis, these were hierarchically classified according to severity, as follows (1) psychotic disorders, depression with psychotic symptoms and bipolar disorder, (2) depression and anxiety, (3) substance use disorder, and (4) other (e.g. dementia, mood disorders and personality and behavior, epilepsy). On account of the small numbers, categories (2), (3) and (4) were grouped together as non-severe mental illness and (1) corresponded to severe mental illness 22. Psychotropic medicines were classified according to the Anatomical Therapeutic Chemical (ATC) classification of the World Health Organization 23.

Characteristics related to the services were obtained from the director of each site. The number of professionals was classified as sufficient and insufficient, considering the Brazilian Ministry of Health recommendation to health services operation. Medicines were classified as sufficient or insufficient based on a qualitative assessment and perception of the availability and variability of medicine lists for prescription by health professionals at the service, as described previously 17 .

\section{Statistical analysis}

A descriptive analysis was carried out followed by bivariate analysis, stratified by gender. Pearson`s Chi-square was used to assess statistical differences in proportions. The magnitude of the associations between explanatory variables and psychotropic polypharmacy was estimated by the odds ratio (OR) with a $95 \%$ confidence interval $(95 \% \mathrm{CI})$ and the level of significance considered was 0.05 .

Multivariate analysis was conducted by logistic regression. Variables with p-values equal to or less than 0.20 in the bivariate analysis were selected to start multivariate modeling. The backward 
stepwise procedure was conducted, i.e. modeling, began with all variables (full model) and sequential deleting of each variable. Only variables with p-values equal to or less than 0.05 remained in the final model. Missing data were excluded from analysis. The likelihood ratio test was used to compare models, and fit was evaluated using the Hosmer-Lemeshow test. Statistical analyses were performed using the SAS 9.4 (SAS Inst., Cary, USA) and Stata 13 (StataCorp LP, College Station, USA) softwares.

\section{Results}

A total of 2,475 (90\%) participants were interviewed. The remaining $10 \%$ of the sample (288) did not participate mainly because of refusal (52\%). There was no statistically significant difference between participants and non-participants with regard to age, sex, schooling and psychiatric diagnoses.

Among the 2,475 participants, 1,277 (51.6\%) were women. Psychotropic medicines were prescribed for $96.0 \%$ of the patients with a mean number of 2.98 psychotropic medicines per patient $(\mathrm{SD}=1.23$ : coefficient of variation $=41 \%$, and median $=3.0)$. Psychotropic polypharmacy occurred in $85.3 \%$ of patients $(\mathrm{N}=2,111$; 95\%CI: $83.8 \%-86.6 \%), 85.7 \%$ among men (95\%CI: $83.6 \%-87.6 \%)$ and $84.9 \%$ among women (95\%CI: $82.8 \%-86.8 \%$; p > 0.05). Non-psychotropic medicines were also prescribed for $31.8 \%$ (95\%CI: $30.0 \%-33.6 \%)$ of the patients (Table 1).

Table 1

Description of psychiatric patients studied. PESSOAS Project, Brazil, $2006(\mathrm{~N}=2,475)$.

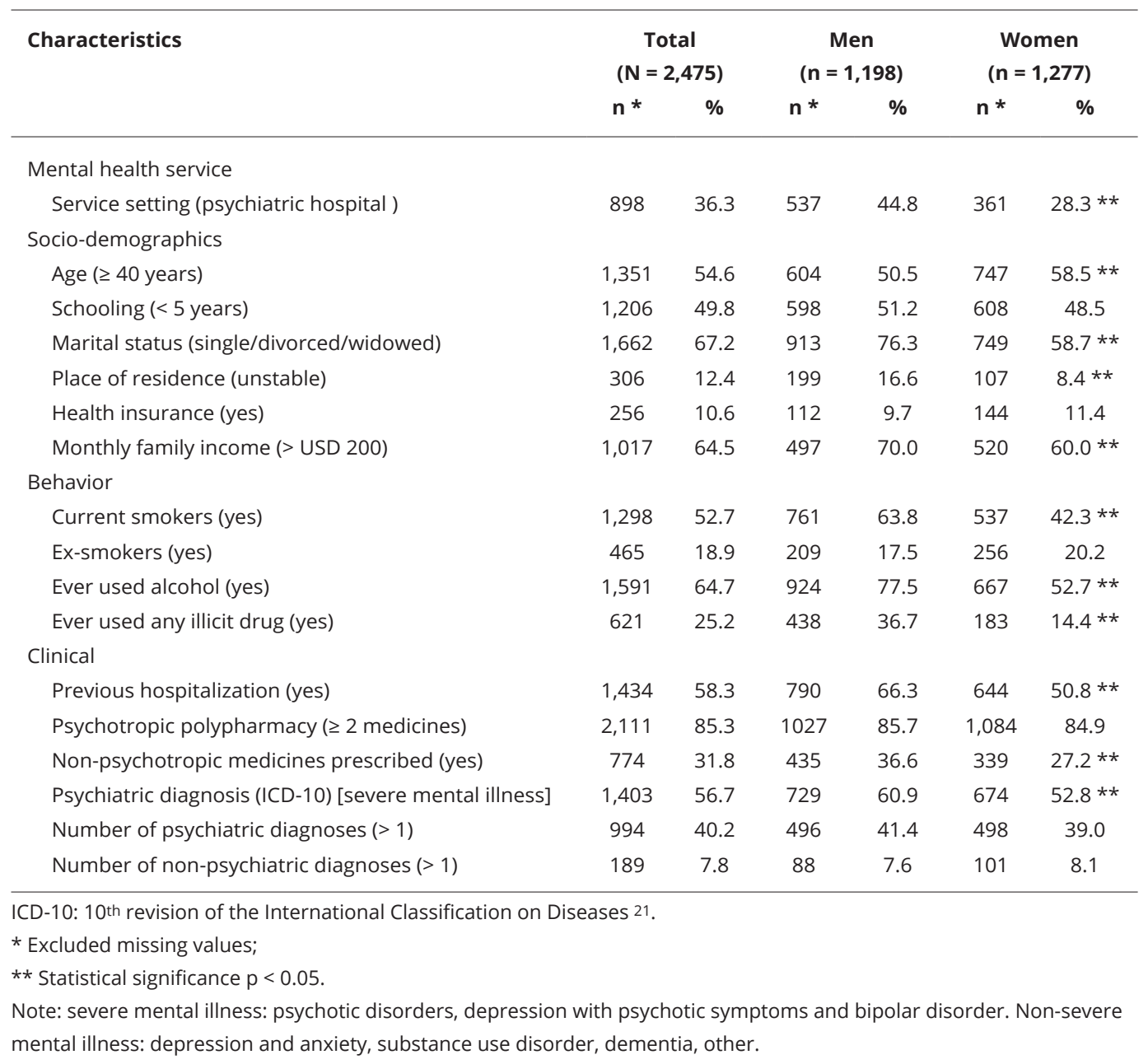


Considering the mental health service, $36.3 \%$ of patients were treated in a psychiatric hospitals, with a greater proportion of men $(44.8 \% ; \mathrm{p}<0.05)$. Regarding socio-demographic characteristics, $54.6 \%$ were 40 years old or over - with women older than men on average $(\mathrm{p}<0.05)$ - and $49.8 \%$ of patients had less than five years of schooling. Men were more often single, divorced or widowed (76.3\% vs. $58.7 \%$ ), had an unstable place of residence (16.6\% vs. $8.4 \%$ ), and had family incomes higher than USD 200 in the last month (70\% vs. 60\%). Only 10.6\% of all patients had health insurance.

There was a high prevalence of current smoking and alcohol use among patients $(52.7 \%$ and $64.7 \%$, respectively) and about a quarter of them declared having used any illicit drug during their lifetime, with men presenting higher rates than women in all of those characteristics.

With respect to clinical characteristics, the majority of patients had been previously hospitalized (58.3\%) and had severe mental illness diagnosis (56.7\%), both with higher prevalence among men $(\mathrm{p}<0.05)$. Moreover, $40.2 \%$ of the patients had more than one psychiatric diagnosis, while only $7.8 \%$ had more than one non-psychiatric diagnosis (Table 1).

Among the 26 services included, $65.4 \%$ were considered to have an insufficient number of professionals (CAPS $=80 \%$; hospitals $=45.5 \%$ ) and $19.2 \%$ to have an insufficient number of mental health medicine available (CAPS $=36.7 \%$; hospitals $=9 \%$ ) (data not shown in tables).

The ten most commonly prescribed medicines were haloperidol (15.7\%), biperiden (10.5\%), diazepam (8.9\%), chlorpromazine (8.7\%), carbamazepine (7.3\%), promethazine (6.9\%), clonazepam (6.4\%), levomepromazine (4.4\%), amitriptyline (3.9\%), and fluoxetine (3.4\%), accounting for about $75 \%$ of all prescription medicine records. Considering the second and third levels of the ATC classification system, the most prescribed medicines were psycholeptics (antipsychotic agents $=37 \%$; anxiolytics $=$ $10 \%$; hypnotics and sedatives $=1 \%$ ), followed by antiepileptics (17\%), psychoanaleptics (antidepressants $=12 \%$ ) and antiparkinsonian (anticholinergic agents $=11 \%$ ) (data not shown in tables).

The same pattern was observed for patients in psychotropic polypharmacy. Antipsychotics were most often combined with other medicines, either in the same class $(37.5 \%)$ or with other classes, including antiepileptics (33.7\%), anticholinergics (33.3\%), anxiolytics (22.2\%), antidepressants (17.9\%), and to a lesser extent with hypnotics and sedatives (2.4\%) (Table 2).

\section{Stratified gender analysis}

The bivariate analysis indicated that for both genders, severe mental illness diagnoses were associated with a higher chance of psychotropic polypharmacy, as well as the number of psychiatric diagnoses and inpatient care (i.e., psychiatric hospital), and self-reported previous hospitalization ( $\mathrm{p}<0.05)$. An insufficient number of professionals in the services was negatively associated with a higher chance of polypharmacy for both genders $(\mathrm{p}<0.05)$. Furthermore, for both genders being single, divorced or widowed, and lifetime illicit drug use were associated with higher psychotropic polypharmacy ( $\mathrm{p}<$ 0.05). Having more than five years of schooling and having health insurance were associated with psychotropic polypharmacy among men only. Among women, more than one non-psychiatric diagnosis and reporting current smoking or alcohol use were associated with psychotropic polypharmacy $(\mathrm{p}<$ 0.05 ). The prescription of non-psychotropic medicines was positively associated with psychotropic medicines among women, and negatively associated among men $(\mathrm{p}<0.05)($ Table 3$)$.

Multivariate analysis revealed that correlates of polypharmacy differed between men and women. For both genders, patients previously hospitalized, with severe mental illness diagnoses, and with more than one psychiatric diagnosis had a higher chance of psychotropic polypharmacy $(\mathrm{p}<0.05)$. Instead, an insufficient number of professionals in the health care unit was negatively associated with psychotropic polypharmacy $(\mathrm{p}<0.05)$. Among men, inpatient care was associated with higher psychotropic polypharmacy, while unstable living and the prescription of any non-psychotropic medicines were negatively associated with psychotropic polypharmacy $(\mathrm{p}<0.05)$. Finally, among women, the prescription of non-psychotropic medicines and lifetime cigarette smoking were associated with a higher chance of psychotropic polypharmacy $(\mathrm{p}<0.05)$ (Table 4$)$. 
Table 2

Description of the combinations of psychotropic medicines prescribed according to the ATC classification. PESSOAS Project, Brazil, $2006(n=2,111)$.

\begin{tabular}{lcc}
\hline ATC classification (3rd level) combination & $\mathbf{n}$ * & \% \\
\hline Same class combination & & 37.5 \\
Antipsychotics & 792 & 9.8 \\
Antiepileptics & 207 & 3.5 \\
Antidepressants & 74 & 0.1 \\
Anxiolytics & 2 & 0.0 \\
Anticholinergics & 1 & \\
Different classes combination & & 33.7 \\
Antipsychotics + Antiepileptics & 712 & 33.3 \\
Antipsychotics + Anticholinergics & 703 & 22.2 \\
Antipsychotics + Anxiolytics & 469 & 17.9 \\
Antipsychotics + Antidepressants & 377 & 14.8 \\
Antiepileptics + Antidepressants & 313 & 13.6 \\
Antiepileptics + Anticholinergics & 288 & 12.0 \\
Antidepressants + Anxiolytics & 253 & 9.7 \\
Anxiolytics + Anticholinergics & 204 & 9.3 \\
Antiepileptics + Anxiolytics & 197 & 6.7 \\
Anticholinergics + Antidepressants & 142 & 2.4 \\
Antipsychotics + Hypnotics and sedatives & 50 & 1.3 \\
Antidepressants + Hypnotics and sedatives & 27 & 1.2 \\
Antiepileptics + Hypnotics and sedatives & 25 & 1.0 \\
Anxiolytics + Hypnotics and sedatives & 22 & 0.8 \\
Anticholinergics + Hypnotics and sedatives & 17 & \\
\hline
\end{tabular}

ATC: Anatomical Therapeutic Chemical classification system 23.

* Included only patients on psychotropic polypharmacy ( $\geq 2$ medicines prescribed).

Table 3

Bivariate analysis of psychotropic polypharmacy, stratified by gender, among patients with mental disorders. PESSOAS Project, Brazil, 2006 ( $N=2,475)$.

\begin{tabular}{|c|c|c|c|c|c|c|c|c|}
\hline \multirow[t]{2}{*}{ Characteristics } & \multicolumn{4}{|c|}{$\operatorname{Men}(n=1,198)$} & \multicolumn{4}{|c|}{ Women $(n=1,277)$} \\
\hline & Total & OR & $95 \% \mathrm{Cl}$ & p-value & Total & OR & $95 \% \mathrm{Cl}$ & p-value \\
\hline \multicolumn{9}{|l|}{ Mental health service } \\
\hline \multicolumn{9}{|l|}{ Service setting } \\
\hline Psychiatric hospital & 537 & 1.65 & $1.18-2.32$ & 0.003 * & 361 & 3.97 & $2.46-6.42$ & $<0.001$ * \\
\hline CAPS & 661 & 1.00 & & & 916 & 1.00 & & \\
\hline \multicolumn{9}{|l|}{ Number of professionals } \\
\hline Insufficient & 743 & 0.57 & $0.39-0.80$ & $0.001 *$ & 355 & 0.62 & $0.42-0.90$ & 0.011 * \\
\hline Sufficient & 455 & 1.00 & & & 922 & 1.00 & & \\
\hline \multicolumn{9}{|l|}{ Number of medicines } \\
\hline Insufficient & 189 & 1.05 & $0.67-1.65$ & 0.825 & 329 & 0.82 & $0.58-1.16$ & 0.262 \\
\hline Sufficient & 1,009 & 1.00 & & & 948 & 1.00 & & \\
\hline
\end{tabular}

(continues) 
Table 3 (continued)

\begin{tabular}{|c|c|c|c|c|c|c|c|c|}
\hline \multirow[t]{2}{*}{ Characteristics } & \multicolumn{4}{|c|}{ Men $(n=1,198)$} & \multicolumn{4}{|c|}{ Women $(n=1,277)$} \\
\hline & Total & OR & $95 \% \mathrm{Cl}$ & p-value & Total & OR & $95 \% \mathrm{Cl}$ & p-value \\
\hline \multicolumn{9}{|l|}{ Socio-demographics } \\
\hline \multicolumn{9}{|l|}{ Age (years) } \\
\hline$\geq 40$ & 604 & 0.79 & 0.57-1.09 & 0.150 & 747 & 1.28 & $0.94-1.74$ & 0.117 \\
\hline$<40$ & 593 & 1.00 & & & 530 & 1.00 & & \\
\hline \multicolumn{9}{|l|}{ Schooling (years) } \\
\hline$<5$ & 598 & 0.67 & $0.48-0.94$ & 0.019 * & 608 & 0.82 & $0.61-1.12$ & 0.219 \\
\hline$\geq 5$ & 569 & 1.00 & & & 645 & 1.00 & & \\
\hline \multicolumn{9}{|l|}{ Marital status } \\
\hline Single/Divorced/Widowed & 913 & 1.44 & $1.01-2.07$ & $0.043^{*}$ & 749 & 1.65 & $1.21-2.24$ & $0.001 *$ \\
\hline Married/Stable union & 284 & 1.00 & & & 528 & 1.00 & & \\
\hline \multicolumn{9}{|l|}{ Place of residence } \\
\hline Unstable & 199 & 0.71 & $0.47-1.06$ & 0.094 & 107 & 1.45 & $0.78-2.70$ & 0.237 \\
\hline Stable & 997 & 1.00 & & & 1168 & 1.00 & & \\
\hline \multicolumn{9}{|l|}{ Health insurance } \\
\hline Yes & 112 & 2.02 & $1.00-4.07$ & 0.046 * & 144 & 0.65 & $0.42-1.00$ & 0.050 \\
\hline No & 1,042 & 1.00 & & & 1,117 & 1.00 & & \\
\hline \multicolumn{9}{|l|}{ Monthly family income (USD) } \\
\hline$>200$ & 497 & 1.11 & $0.70-1.77$ & 0.664 & 520 & 0.72 & $0.50-1.05$ & 0.088 \\
\hline$\leq 200$ & 213 & 1.00 & & & 346 & 1.00 & & \\
\hline \multicolumn{9}{|l|}{ Behavior } \\
\hline \multicolumn{9}{|l|}{ Smoking } \\
\hline Current smoker & 761 & 1.24 & $0.89-1.74$ & 0.195 & 537 & 2.00 & $1.43-2.80$ & $<0.001$ * \\
\hline Ex-smoker & 209 & 0.95 & $0.62-1.44$ & 0.795 & 256 & 1.10 & $0.75-1.63$ & 0.621 \\
\hline Non-smoker & 222 & 1.00 & & & 476 & 1.00 & & \\
\hline \multicolumn{9}{|l|}{ Alcohol use (ever) } \\
\hline Yes & 924 & 1.24 & $0.85-1.80$ & 0.262 & 667 & 1.44 & $1.05-1.96$ & $0.021 *$ \\
\hline No & 269 & 1.00 & & & 598 & 1.00 & & \\
\hline \multicolumn{9}{|l|}{ Any illicit drug use (ever) } \\
\hline Yes & 438 & 1.75 & $1.22-2.51$ & 0.002 * & 183 & 3.47 & $1.80-6.69$ & $<0.001$ * \\
\hline No & 755 & 1.00 & & & 1,090 & 1.00 & & \\
\hline \multicolumn{9}{|l|}{ Clinical } \\
\hline \multicolumn{9}{|c|}{ Self-reported previous hospitalization } \\
\hline Yes & 790 & 1.91 & $1.38-2.65$ & $<0.001$ * & 644 & 4.71 & $3.26-6.78$ & $<0.001$ * \\
\hline No & 402 & 1.00 & & & 623 & 1.00 & & \\
\hline \multicolumn{9}{|c|}{ Non psychotropic medicines prescribed } \\
\hline Yes & 435 & 0.70 & $0.51-0.98$ & 0.037 * & 339 & 2.78 & $1.76-4.39$ & $<0.001$ * \\
\hline No & 753 & 1.00 & & & 909 & 1.00 & & \\
\hline \multicolumn{9}{|l|}{ Psychiatric diagnosis (ICD-10) } \\
\hline Severe mental illness & 729 & 2.74 & $1.96-3.81$ & $<0.001$ * & 674 & 5.20 & $3.61-7.50$ & 0.000 * \\
\hline Non-severe mental illness & 469 & 1.00 & & & 603 & 1.00 & & \\
\hline \multicolumn{9}{|c|}{ Number of psychiatric diagnoses } \\
\hline$>1$ & 496 & 1.74 & $1.23-2.47$ & 0.002 * & 498 & 4.95 & $3.22-7.62$ & $<0.001$ * \\
\hline$\leq 1$ & 702 & 1.00 & & & 779 & 1.00 & & \\
\hline \multicolumn{9}{|c|}{ Number of non-psychiatric diagnoses } \\
\hline$>1$ & 88 & 0.73 & $0.41-1.29$ & 0.273 & 101 & 3.47 & $1.39-8.67$ & 0.005 * \\
\hline$\leq 1$ & 1,077 & 1.00 & & & 1,148 & 1.00 & & \\
\hline
\end{tabular}

95\%Cl: 95\% confidence interval; CAPS: Psychosocial Care Centers; ICD-10: 10th revision of the International Classification of Diseases 21; OR: odds ratio. * Statistical significance $p<0.05$.

Note: excluded missing values. Severe mental illness: psychotic disorders, depression with psychotic symptoms and bipolar disorder. Non-severe mental illness: depression and anxiety, substance use disorder, dementia, other. 
Multivariate analysis of psychotropic polypharmacy, stratified by sex, among patients with mental disorders. PESSOAS Project, Brazil, 2006 ( $N=2,245)$.

\begin{tabular}{|c|c|c|c|c|}
\hline \multirow[t]{2}{*}{ Characteristics } & \multicolumn{2}{|c|}{$\begin{array}{c}\text { Men * } \\
(n=1,078)\end{array}$} & \multicolumn{2}{|c|}{$\begin{array}{l}\text { Women ** } \\
(n=1,167)\end{array}$} \\
\hline & OR $(95 \% \mathrm{Cl})$ & p-value & OR $(95 \% \mathrm{Cl})$ & p-value \\
\hline \multicolumn{5}{|l|}{ Mental health service } \\
\hline Service setting (psychiatric hospital) & $2.00(1.23-3.24)$ & $0.005 * * *$ & - & - \\
\hline Number of professionals (insufficient) & $0.61(0.39-0.96)$ & $0.033 * \star \star$ & $0.61(0.38-0.97)$ & $0.035 * \star \star$ \\
\hline \multicolumn{5}{|l|}{ Socio-demographics } \\
\hline Place of residence (unstable) & $0.50(0.30-0.83)$ & $0.007 * \star *$ & - & - \\
\hline \multicolumn{5}{|l|}{ Behavior } \\
\hline Current smoker (yes) & - & - & $1.91(1.27-2.87)$ & $0.002 * \star \star$ \\
\hline Ex-smoker (yes) & - & - & $1.54(0.96-2.45)$ & 0.072 \\
\hline \multicolumn{5}{|l|}{ Clinical } \\
\hline Self-reported previous hospitalization (yes) & $1.59(1.10-2.29)$ & $0.014 * * *$ & $2.56(1.68-3.89)$ & $<0.001 * * *$ \\
\hline Psychiatric diagnosis (severe mental illness) & $2.61(1.81-3.77)$ & $<0.001 * * *$ & $2.91(1.93-4.39)$ & $<0.001 * * *$ \\
\hline Number of psychiatric diagnoses $(>1)$ & $1.56(1.07-2.27)$ & $0.022 * \star \star$ & $3.90(2.48-6.12)$ & $<0.001 * * *$ \\
\hline Non psychotropic medicines prescribed (yes) & $0.58(0.38-0.86)$ & $0.009 * \star \star$ & $1.96(1.19-3.18)$ & $0.008 * \star *$ \\
\hline
\end{tabular}

* Hosmer-Lemeshow test: $\chi^{2}=10.71 ; d f=8 ; p=0.219$;

** Hosmer-Lemeshow test: $\chi^{2}=6.45 ; \mathrm{df}=8 ; \mathrm{p}=0.597$;

$* * *$ Statistical significance $\mathrm{p}<0.05$.

Note: excluded missing values. Severe mental illness: psychotic disorders, depression with psychotic symptoms and bipolar disorder. Non-severe mental illness: depression and anxiety, substance use disorder, dementia, other.

\section{Discussion}

The use of psychotropic medicines and the occurrence of psychotropic polypharmacy were common therapeutic approaches in this nationwide sample of patients with mental illness in Brazil. The proportion of polypharmacy in this population was high and similar among genders, despite the fact that factors independently associated with psychotropic polypharmacy varied among them.

Cross-sectional studies have shown that the use of psychotropic medicines is quite common in the general population. In Brazil, the prevalence of psychotropic use ranged from $6.5 \%$ to $13.3 \%$ 9,10,24, with an emphasis on the use of antidepressants, which were more common among women 9 . In addition, only $16 \%$ of patients with a mental disorder were treated with psychotropic agents 9 , contrasting with the high rate of prescriptions of these medicines in our study (96\%). These differences may be due to the population, since our sample contains more severe cases than in the general population, and also due to the source of information obtained about the use of medicines (self-reported vs. medical chart register) and the diagnoses evaluated (self-reported vs. medical chart as registered by physicians). Moreover, the difficulty of general practitioners to diagnose and treat patients with mental disorders in primary care settings and barriers of access to specialized health services 25 may also help to explain these differences.

Studies have shown that psychotropic polypharmacy among patients with psychiatric disorders varies from $10 \%$ to $93 \% 13,26,27,28,29,30$, in line with the psychotropic polypharmacy prevalence of 85.3\% in our national sample. A trend of enhancing polypharmacy among psychiatric patients has been observed, with a decline in monotherapy strategy over the years from $47.8 \%$ in the 1970 s, to $19.6 \%$ in the $1990 \mathrm{~s} 31$. This can also be observed in the mean number of psychotropic medications prescribed per individual. A combined analysis of 28 studies involving 23,428 patients showed a mean of 2.47 ( 1.5 to 4.0 ) psychotropic medicines/institutionalized patient 31 . In recent studies this number is even higher (2.8) 28, as was observed in our study (2.98). 
Regarding risk factors relating to psychotic polypharmacy, we found that severe mental illness diagnoses were associated with psychotic polypharmacy for both men and women and almost $60 \%$ of the patients had severe mental illness diagnosis. The literature describes primary psychiatric diagnosis as one of the most important factors associated with psychotropic polypharmacy: patients with severe mental illnesses such as schizophrenia, depression with psychotic symptoms, and bipolar disorders are at greater risk of polypharmacy and increased use of psychotropic medicines 13,26,30,32,33.

Patients with multiple psychiatric diagnoses also had increased chances of polypharmacy. These findings are corroborated by other studies, which pointed to an association between polypharmacy and markers of more severe illness, such as the number of psychiatric diagnoses 15 , non-psychiatric comorbidities 12 , and previous hospitalization 34 . This could partially be explained by actual need of different drugs or monotherapy-refractory conditions that require changes in prescription regimens. Furthermore, similar to other countries, the reduction in the number of psychiatric hospital beds in Brazil may have resulted in discharge of patients with clinically severe conditions, meaning there is a greater need of medicalization in order to facilitate social interaction 13,31, despite the lack of evidence to support these inferences 27 .

We observed an independent association between psychotropic polypharmacy and current cigarette smoking among women only. Studies in the general population have shown the association between smoking and the simultaneous use of four or more medicines 35 and also with psychotropic medicines 24 . In addition, previous studies among psychiatric patients indicate an association between current smoking and substance use disorder diagnoses, but not with ex-smokers 36 . Current smokers with substance use disorder diagnoses may be more refractory to smoking cessation and potentially in need of more adjuvant therapy. Whether this is only the case among women needs further investigation and studies are needed to clarify this association.

Among men, being currently hospitalized was associated with higher psychotropic polypharmacy, while having an unstable place of residence (living in shelters, hostels, streets, hospital), as well as having a prescription for non-psychotropic medicines were associated with less psychotropic polypharmacy. We did not find any study that considered these two treatment settings (hospital and CAPS). However, a Brazilian study conducted in 2005 found that elderly patients with length of hospitalization of between 12 and 35 months had less polypharmacy than newly institutionalized patients, probably because at the time of admission these patients had greater severity and instability of the disease 37 . Minor antipsychotic polypharmacy in hospitalized and homeless patients occurred in in-patient facilities in Italy in 2002-2003 26. These studies are consistent with our findings, in which patients in current treatment at the hospitals, with greater severity of illness, showed greater polypharmacy, while those living in unstable conditions had lower polypharmacy.

In our study, the most prescribed medicines were haloperidol, biperiden, diazepam, and chlorpromazine, as reported in East Asia for schizophrenic patients 27. Antipsychotics were the most prescribed medicines (37\%) and the most commonly used combinations involved these agents, as observed in other studies $13,28,30$. However, antipsychotic polypharmacy is quite controversial in the literature. It has been associated with higher prescriptions of adjunctive medications such as anticholinergic and anti-parkinsonian medicines 26,27; higher daily dosages and higher rates of adverse events 14 .

The negative association between insufficiency of psychiatric professionals and lower polypharmacy deserves attention. It should be noted that proper diagnostic assessment and the need for psychotropic prescription is better ascertained by trained psychiatric professionals. It is likely that this association is only a marker for a lack of psychiatrists, thus patients are not being evaluated for the use of psychotropic medicines. We should also note that the variable insufficient availability of medicines' was also found to be in the same direction in the univariate analysis, though it was not statistically significant.

Regarding the availability of psychotropic medicines, in $80.8 \%$ of the Brazilian psychiatric services this availability was considered sufficient. However, for most services $(92.3 \%)$ the standardized medicine list included mainly first generation antipsychotic agents (e.g. haloperidol, chlorpromazine, lithium carbonate) 17 . According to a recent Chinese study, the reduced availability of therapeutic classes can potentially be associated with polypharmacy utilization 38 . The updated RENAME did not include antipsychotic agents, but did include two anti-parkinson drugs (cabergoline and 
levodopa+benserazide) and one hypnotics and sedative - midazolam. Alternatively, second-generation antipsychotics (clozapine, risperidone, olanzapine, quetiapine, and ziprasidone), other antiparkinson drugs (amantadine, bromocriptine, entacapone, pramipexole, selegiline, tolcapone), other antiepileptics (ethosumide, gabapentin, lamotrigine, primidone, topiramate, trihexyphenidyl, vigabratrin) and the anxiolytic clobazam are provided by the Brazilian Unified National Health System (SUS) through the specialized component of pharmaceuticals in line with specific criteria 39.

Another barrier to the quality of care in mental health that can contribute to the occurrence of psychotropic polypharmacy is the lack of a national guidelines for prescribing practices in psychiatric care, considering the medicine-based evidence principles. These guidelines should address when polypharmacy is appropriated, for example, in short periods to control the exacerbation of symptoms, to prevent adverse events after increasing the dose of a single agent, or in patients that have been refractory to monotherapy 26,40,41. Case management, continuing education, treatment algorithms, reminders and feedbacks, and pharmaceutical care are other approaches that can be used to avoid inappropriate psychotropic prescribing 41 .

Some limitations of the study should be pointed out. We were not able to address polypharmacy with regard to its duration and reasons for using more than one medication, and this should be further explored in future studies. The definition of psychotropic polypharmacy as the use of two or more psychotropic medicines led to a high rate of this event in this population, and therefore, the effect size of the associated factors may be potentially overestimated by the use of logistic regression. Psychiatric diagnoses were collected from medical charts and there was a limit of seven psychiatric medications that could be collected. Also, because the sample size was not a priori calculated to study polypharmacy stratified by gender, we may have had limited power to detect differences among selected variables with small numbers in both groups. Finally, the study design limits the establishment of direct causality. The associations observed are only indicators of potential causal effect and they may contain residual confounding due to unmeasured variables. In addition, due to the scarcity of literature in the field regarding this population, comparisons are limited and other studies are needed to confirm these findings.

\section{Conclusion}

In this nationwide sample of psychiatric patients, psychotropic medicine utilization and psychotropic polypharmacy were common practices, with differences in the set of associated factors among genders. There is a need for developing national guidelines to manage patients with mental illness, which should consider the role of gender and disease severity. Other strategies such as case management, continuing education and pharmaceutical care can also contribute to the reduction of the burden of polyphamacy in this population. 


\section{Contributors}

J. O. Costa carried out the data analysis and interpretation, critical revision of relevant content and approval of final version for publication, as well as overseeing all stages of the research to guarantee the precision and integrity of all elements of the study. M. G. B. Ceccato carried out the data interpretation, write-up of the article and approval of final version for publication, as well as overseeing all stages of the research to guarantee the precision and integrity of all elements of the study. A. P. S. Melo contributed towards the data analysis and interpretation, article write-up and approval of the final version for publication. F. A. Acurcio contributed towards the project design, critical revision of relevant content and approval of the final version for publication. M. D. C. Guimarães contributed towards the project design, data analysis and interpretation, critical revision of relevant content and approval of the final version for publication.

\section{Acknowledgments}

This study was carried out by the UFMG with technical and financial support from the Ministry of Health/Secretariat of Health Surveillance/Department of STDs, AIDS and Viral Hepatitis through the International Technical Cooperation Project 914/ BRA/1101 between the Brazilian Government and the United Nations Educational, Scientific and Cultural Organization (UNESCO).

\section{Conflict of interest}

The authors declare no conflict of interests.

\section{References}

1. Whiteford HA, Degenhardt L, Rehm J, Baxter AJ, Ferrari AJ, Erskine HE, et al. Global burden of disease attributable to mental and substance use disorders: findings from the Global Burden of Disease Study 2010. Lancet 2013; 382:1575-86.

2. Viana MC, Andrade LH. Lifetime prevalence, age and gender distribution and age-of-onset of psychiatric disorders in the São Paulo Metropolitan Area, Brazil: results from the São Paulo Megacity Mental Health Survey. Rev Bras Psiquiatr 2012; 34:249-60.

3. Afifi M. Gender differences in mental health. Singapore Med J 2007; 48:385-91.

4. Gispert R, Rajmil L, Schiaffino A, Herdman M. Sociodemographic and health-related correlates of psychiatric distress in a general population. Soc Psychiatry Psychiatr Epidemiol 2003; 38:677-83.

5. Bijl RV, De Graaf R, Ravelli A, Smit F, Vollebergh WA; Netherlands Mental Health Survey and Incidence Study. Gender and age-specific first incidence of DSM-III-R psychiatric disorders in the general population. Results from the Netherlands Mental Health Survey and Incidence Study (NEMESIS). Soc Psychiatry Psychiatr Epidemiol 2002; 37:372-9.

6. Pedersen CB, Mors O, Bertelsen A, Waltoft BL, Agerbo E, McGrath JJ, et al. A comprehensive nationwide study of the incidence rate and lifetime risk for treated mental disorders. JAMA Psychiatry 2014; 71:573-81.

7. Kessler RC, McGonagle KA, Zhao S, Nelson CB, Hughes M, Eshleman S, et al. Lifetime and 12 -month prevalence of DSM-III-R psychiatric disorders in the United States. Results from the National Comorbidity Survey. Arch Gen Psychiatry 1994; 51:8-19.

8. Jané-Llopis E, Matytsina I. Mental health and alcohol, drugs and tobacco: a review of the comorbidity between mental disorders and the use of alcohol, tobacco and illicit drugs. Drug Alcohol Rev 2006; 25:515-36.

9. Quintana MI, Andreoli SB, Moreira FG, Ribeiro WS, Feijo MM, Bressan RA, et al. Epidemiology of psychotropic drug use in Rio de Janeiro, Brazil: gaps in mental illness treatments. PLoS One 2013; 8:e62270.

10. Lima MC, Menezes PR, Carandina L, Cesar CL, Barros MB, Goldbaum M. Transtornos mentais comuns e uso de psicofármacos: impacto das condições socioeconômicas. Rev Saúde Pública 2008; 42:717-23.

11. Hahn M, Braus DF. Psychiatric polypharmacy: hazard through drug-drug-interaction and possibilities for prevention. Versicherungsmedizin 2012; 64:127-31.

12. Viola R, Csukonyi K, Doró P, Janka Z, Soós G. Reasons for polypharmacy among psychiatric patients. Pharm World Sci 2004; 26:143-7.

13. De las Cuevas C, Sanz EJ. Polypharmacy in psychiatric practice in the Canary Islands. BMC Psychiatry 2004; 4:18.

14. Tranulis C, Skalli L, Lalonde P, Nicole L, Stip E. Benefits and risks of antipsychotic polypharmacy: an evidence-based review of the literature. Drug Saf 2008; 31:7-20. 
15. Mojtabai R, Olfson M. National trends in psychotropic medication polypharmacy in officebased psychiatry. Arch Gen Psychiatry 2010; 67:26-36.

16. Guimarães MD, Campos LN, Melo AP, Carmo RA, Machado CJ, Acurcio FA, et al. Prevalence of HIV, syphilis, hepatitis B and C among adults with mental illness: a multicenter study in Brazil. Rev Bras Psiquiatr 2009; 31:43-7.

17. Melo APS, Acúrcio FA, Cherchiglia ML, Guimarães CC, Veloso MDCG. Avaliação de serviços de saúde mental: assistência e prevenção às doenças sexualmente transmissíveis no contexto do Projeto PESSOAS. Rev Méd Minas Gerais 2007; 17(1/2, Suppl 4):S240-8.

18. Guimarães MD, Oliveira HN, Campos LN, Santos CA, Gomes CE, Oliveira SB, et al. Reliability and validity of a questionnaire on vulnerability to sexually transmitted infections among adults with chronic mental illness: PESSOAS Project. Rev Bras Psiquiatr 2008; 30:55-9.

19. Departamento de Ações Programáticas Estratégicas, Secretarias de Atenção à Saúde, Ministério da Saúde. Saúde mental no SUS: os centros de atenção psicossocial. Brasília: Ministério da Saúde; 2004. (Série F. Comunicação e Educação em Saúde).

20. Departamento de Assistência Farmacêutica e Insumos Estratégicos, Secretaria de Ciência, Tecnologia e Insumos Estratégicos, Ministério da Saúde. Relação Nacional de Medicamentos Essenciais - RENAME. 5a Ed. Brasília: Ministério da Saúde; 2007.

21. World Health Organization. ICD-10: international statistical classification of diseases and related health problems, 10th revision. Geneva: World Health Organization; 2004.

22. Schinnar AP, Rothbard AB, Kanter R, Jung YS. An empirical literature review of definitions of severe and persistent mental illness. Am J Psychiatry 1990; 147:1602-8.

23. WHO Collaborating Centre for Drug Statistics Methodology; Norwegian Institute of Public Health. ATC/DDD index database. http:// www.whocc.no/atc_ddd_index/ (accessed on 18/Apr/2013).

24. Rodrigues MA, Facchini LA, Lima MS. Modificações nos padrões de consumo de psicofármacos em localidade do Sul do Brasil. Rev Saúde Pública 2006; 40:107-14.

25. Ballester DA, Filippon AP, Braga C, Andreoli $\mathrm{SB}$. The general practitioner and mental health problems: challenges and strategies for medical education. São Paulo Med J 2005; 123:72-6.

26. Santone G, Bellantuono C, Rucci P, Picardi A, Preti A, Girolamo G. Patient characteristics and process factors associated with antipsychotic polypharmacy in a nationwide sample of psychiatric inpatients in Italy. Pharmacoepidemiol Drug Saf 2011; 20:441-9.

27. Sim K, Su A, Fujii S, Yang SY, Chong MY, Ungvari GS, et al. Antipsychotic polypharmacy in patients with schizophrenia: a multicentre comparative study in East Asia. Br J Clin Pharmacol 2004; 58:178-83.
28. Jordanova V, Maric NP, Alikaj V, Bajs M, Cavic $\mathrm{T}$, Iosub D, et al. Prescribing practices in psychiatric hospitals in Eastern Europe. Eur Psychiatry 2011;26:414-8.

29. Sarkar P, Chakraborty K, Misra A, Shukla R, Swain SP. Pattern of psychotropic prescription in a tertiary care center: a critical analysis. Indian J Pharmacol 2013; 45:270-3.

30. Adeponle AB, Obembe AO, Adeyemi SO, Suleiman GT. Polypharmacy in psychiatric outpatient practice in northern Nigeria. Afr J Psychiatry (Johannesbg) 2007; 10:215-8.

31. Rittmannsberger $\mathrm{H}$. The use of drug monotherapy in psychiatric inpatient treatment. Prog Neuropsychopharmacol Biol Psychiatry 2002; 26:547-51.

32. Bernardo M, Coma A, Ibáñez C, Zara C, Bari JM, Serrano-Blanco A. Antipsychotic polypharmacy in a regional health service: a populationbased study. BMC Psychiatry 2012; 12:42.

33. Morrato EH, Dodd S, Oderda G, Haxby DG, Allen R, Valuck RJ. Prevalence, utilization patterns, and predictors of antipsychotic polypharmacy: experience in a multistate Medicaid population, 1998-2003. Clin Ther 2007; 29:183-95.

34. Suokas JT, Suvisaari JM, Haukka J, Korhonen P, Tiihonen J. Description of long-term polypharmacy among schizophrenia outpatients. Soc Psychiatry Psychiatr Epidemiol 2013; 48:631-8.

35. Pappa E, Kontodimopoulos N, Papadopoulos AA, Tountas Y, Niakas D. Prescribed-drug utilization and polypharmacy in a general population in Greece: association with sociodemographic, health needs, health-services utilization, and lifestyle factors. Eur J Clin Pharmacol 2011; 67:185-92.

36. Barros FC, Melo AP, Cournos F, Cherchiglia ML, Peixoto ER, Guimarães MD. Cigarette smoking among psychiatric patients in Brazil. Cad Saúde Pública 2014; 30:1195-206.

37. Lucchetti G, Granero AL, Pires SL, Gorzoni ML. Fatores associados à polifarmácia em idosos institucionalizados; Factors associated to polypharmacy in institutionalized elderly. Rev Bras Geriatr Gerontol 2010; 13:51-8.

38. Li Q, Xiang YT, Su YA, Shu L, Yu X, Chiu HF, et al. Antipsychotic polypharmacy in schizophrenia patients in China and its association with treatment satisfaction and quality of life: findings of the third national survey on use of psychotropic medications in China. Aust N Z J Psychiatry 2015; 49:129-36.

39. Departamento de Assistência Farmacêutica e Insumos Estratégicos, Secretaria de Ciência, Tecnologia e Insumos Estratégicos, Ministério da Saúde. Relação Nacional de Medicamentos Essenciais - RENAME. 9a Ed. Brasília: Ministério da Saúde; 2015.

40. Sernyak MJ, Rosenheck R. Clinicians' reasons for antipsychotic coprescribing. J Clin Psychiatry 2004; 65:1597-600.

41. Kukreja S, Kalra G, Shah N, Shrivastava A. Polypharmacy in psychiatry: a review. Mens Sana Monogr 2013; 11:82-99. 


\section{Resumo}

Os autores tiveram como objetivo estimar a prevalência da polifarmácia psicotrópica e fatores associados entre pacientes psiquiátricos brasileiros, segundo o gênero. Foram obtidos dados sociodemográficos, comportamentais e clínicos por meio de entrevistas presenciais e prontuários médicos de 2.475 pacientes. A polifarmácia psicotrópica foi definida como o uso de dois ou mais medicamentos psicotrópicos, e foi constatada em $85,7 \%$ dos homens (IC95\%: 83,6\%-87,6\%) e 84,9\% das mulheres (IC95\%: 82,8\%-86,8\%; p > 0,05). A média de medicamentos psicotrópicos por paciente foi $2,98 \pm$ 1,23 , e as combinações mais comuns incluíam os antipsicóticos. A análise multivariada mostrou que, para ambos os gêneros, internação hospitalar prévia, doença psiquiátrica grave, múltiplos diagnósticos psiquiátricos e número insuficiente de profissionais na unidade de saúde foram associados à polifarmácia psicotrópica. Entretanto, fatores como cuidados hospitalares, uso de drogas não-psicotrópicas, condições de vida instáveis e tabagismo atual variaram de acordo com o gênero. A polifarmácia psicotrópica foi uma prática comum nessa amostra nacional. Os resultados evidenciam a necessidade de diretrizes nacionais para o manejo de pacientes com transtornos mentais, considerando a diferença entre gêneros e a gravidade da doença, para reduzir a carga da polifarmácia nessa população de pacientes.

Polimedicação; Psicotrópicos; Transtornos Mentais; Gênero e Saúde

\section{Resumen}

El objetivo de los autores fue estimar la prevalencia de la polifarmacia psicotrópica y factores asociados entre pacientes psiquiátricos brasileños, según con el género. Se obtuvieron datos sociodemográficos, comportamentales y clinicos, a través de entrevistas presenciales y registros médicos de 2.475 pacientes. La polifarmacia psicotrópica se definió como el uso de dos o más medicamentos psicotrópicos, $y$ fue constatada en un $85,7 \%$ de los hombres (IC95\%: 83,6\%-87,6\%) y en un 84,9\% de las $m u-$ jeres (IC95\%: 82, 8\%-86,8\%; $p>0,05$ ). La media de medicamentos psicotrópicos por paciente fue de 2,98 $\pm 1,23$, y las combinaciones más comunes incluían los antipsicóticos. El análisis multivariado mostró que, para ambos géneros, el internamiento hospitalario previo, enfermedad psiquiátrica grave, múltiples diagnósticos psiquiátricos, y número insuficiente de profesionales en la unidad de salud, estuvieron asociados a la polifarmacia psicotrópica. Asimismo, otros correlatos, tales como cuidados hospitalarios, uso de medicamentos no-psicotrópicos, condiciones de vida inestables y tabaquismo actual variaron de acuerdo con el género. La polifarmacia psicotrópica fue una práctica común en esa muestra nacional. Los resultados destacan la necesidad de directrices nacionales para cuidar de pacientes con trastornos mentales, considerando la diferencia entre géneros y la gravedad de la enfermedad, para reducir la carga de la polifarmacia en esa población de pacientes.

Polifarmacia; Psicotrópicos; Trastornos Mentales; Género y Salud
Submitted on $14 /$ Oct $/ 2015$

Final version resubmitted on 28/Mar/2016

Approved on 19/Aug/2016 